\title{
In memoriam: Dr. Arturo Almazán Enríquez
}

In memoriam: Dr Arturo Almazán Enríquez 


\section{In memoriam: Dr. Arturo Almazán Enríquez}

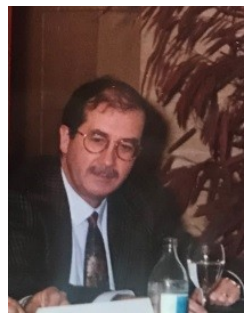

Sr. Director:

Arturo Almazán Enríquez (Moralaja del Vino, Zamora, 1944Salamanca, 2021), fue un pionero de la cirugía vascular en nuestro país. Después de licenciarse en Medicina por la Universidad Complutense de Madrid y especializarse en Cirugía General, decidió que sería útil ampliar su formación en el extranjero. Eligió para tal misión el St. Mary's Hospital (Londres, Inglaterra). Allí permaneció tres años a las órdenes de los doctores Eastcott y Nicolaides. Con ambos hizo gran amistad, hasta el punto de que todas las Navidades les enviaba turrón. En St. Mary's aprendió las técnicas vasculares de la época y los novedosos métodos de exploración vascular que por entonces se desarrollaban en el laboratorio del profesor Irvine.

Retornó a España, concretamente a Salamanca, que en 1975 estrenaba nuevo hospital universitario. El Prof. Gómez Alonso, jefe del Departamento de Cirugía de mencionado hospital le indicó que creara un laboratorio vascular y coordinara un grupo de facultativos con interés preferencial hacia la patología vascular. Por esa época, siendo yo alumno interno, conocí al Dr. Almazán y tuve la oportunidad de asistir a sus primeras operaciones sobre la aorta; él personalmente me enseñó a realizar el índice T/B, que durante su estancia londinense aprendió directamente del propio Dr. Yao. En mis primeros años de residente roté con él y con su compañero y amigo, el Dr. Ramos, y me permitieron trabajar junto a ellos, realizando 
pletismografías, presiones venosas ambulatorias o simpatectomías lumbares químicas, que dieron lugar a mis primeras publicaciones.

Si mi memoria no me engaña, el Dr. Almazán fue el primero en Salamanca en publicar un trabajo en inglés (Vascular Surgery, 1983) o llevar comunicaciones a un congreso en el extranjero (Londres, 1981). Durante su estancia en Salamanca, primero convalidó su título de especialista en cirugía vascular, que años antes había obtenido en el Royal College of Surgeons of England, realizó su tesis doctoral y fue nombrado profesor ayudante en la Universidad de Salamanca. Vicisitudes de la vida le obligaron a orientar su vida profesional a la actividad privada, donde alcanzó un reconocido prestigio.

En el ámbito nacional, el Dr. Almazán rápidamente ingresó como miembro numerario de la SEACV, colaboró con la sociedad en muchos congresos y publicó numerosos artículos en Angiología.

Arturo Almazán Enríquez, sin ninguna duda, fue un pionero de la cirugía vascular salmantina. Una larga enfermedad, que acabó con su vida (8 julio de 2021), nos mostró nuevamente sus cualidades humanas. Yo le recordaré por sus enseñanzas y su humor "inglés" y amistad.

DEP.

Francisco S. Lozano Sánchez

Servicio de Angiología y Cirugía Vascular. Hospital Universitario de Salamanca. Salamanca

e-mail: lozano@usal.es 